University of Nebraska - Lincoln

DigitalCommons@University of Nebraska - Lincoln

\title{
Electrical control of the thermodiffusive instability in premixed propane-air flames
}

\author{
D. L. Wisman \\ Miami University \\ S. D. Marcum \\ Miami University \\ B. N. Ganguly \\ Air Force Research Laboratory
}

Follow this and additional works at: https://digitalcommons.unl.edu/usafresearch

Part of the Aerospace Engineering Commons

Wisman, D. L.; Marcum, S. D.; and Ganguly, B. N., "Electrical control of the thermodiffusive instability in premixed propane-air flames" (2007). U.S. Air Force Research. 32.

https://digitalcommons.unl.edu/usafresearch/32

This Article is brought to you for free and open access by the U.S. Department of Defense at DigitalCommons@University of Nebraska - Lincoln. It has been accepted for inclusion in U.S. Air Force Research by an authorized administrator of DigitalCommons@University of Nebraska - Lincoln. 


\title{
Electrical control of the thermodiffusive instability in premixed propane-air flames
}

\author{
D.L. Wisman ${ }^{\mathrm{a}, 1}$, S.D. Marcum ${ }^{\mathrm{a}}$, B.N. Ganguly ${ }^{\mathrm{b}, *}$ \\ ${ }^{a}$ Department of Physics, Miami University, Oxford, OH 45056, USA \\ ${ }^{\mathrm{b}}$ Air Force Research Laboratory, Wright-Patterson AFB, OH 45433, USA
}

Received 16 November 2006; received in revised form 10 June 2007; accepted 18 June 2007

Available online 29 October 2007

\begin{abstract}
This work focuses upon the effects of DC electric fields on the stability of downward propagating atmospheric pressure premixed propane-air flames under experimental conditions that provide close coupling of the electric field to the flame. With the appropriate electrode geometry, modest applied voltages are shown to drive a stable conical flame first into a wrinkled-laminar flamelet geometry, and then further toward either a highly unstable distributed flamelet regime or a collective oscillation of the flame front. Applied potentials up through $+5 \mathrm{kV}$ over a 40-mm gap encompassing the flame front have been used to force the above transition sequence in flames with equivalence ratios between 0.8 and 1.3 and flow velocities up to $1.7 \mathrm{~m} / \mathrm{s}$. Experiments are reported that characterize the field-induced changes in the geometry of the reaction zone and the structure of the resulting unstable flame. The former is quantified by combustion intensity enhancement estimates derived from high-speed two-dimensional direct and spectroscopic imaging of chemiluminescence signals. The flame fluid mechanical response to the applied field, brought about by forcing positive flame ions counter to the flow, drives the effective flame Lewis number to values suitable for the onset of the thermodiffusive instability, even near stoichiometric conditions. Possible field-driven flame ion recombination chemistry that would produce light reactants near the burner head and precipitate the onset of the thermodiffusive instability is proposed. Electrical measurements are also reported that establish that minimal electrical power input is required to produce the observed flame instabilities. Current continuity-based calculations allow estimates of the level of deficient light reactant necessary to cause the flame to become unstable. This applied-electric-field-induced modification of the thermodiffusive effect could serve as a potentially attractive means of controlling flame fluid-mechanical characteristics and validating combustion instability models over a wide range of equivalence ratios.

Published by Elsevier Inc. on behalf of The Combustion Institute.
\end{abstract}

Keywords: Hydrocarbon combustion; Electric field; Ionic recombination; Thermodiffusive instability; Flame speed

\section{Introduction}

\footnotetext{
* Corresponding author. Fax: +1 9376564095.

E-mail address: biswa.ganguly@wpafb.af.mil

(B.N. Ganguly).

1 Currently with UES Inc., 4401 Dayton-Xenia Rd., Dayton, $\mathrm{OH} 45432$, USA.
}

It is widely known [1-4] that the observed stability in a premixed flame is actually due to the competition between three instabilities (hydrodynamic, thermodiffusive, and body-force) in the flame. The body-force 
instability inherent to a flame is most prominent in flames that are slowly propagating in an upward direction; thus for the experimental conditions of interest here it is possible to neglect the effects due to the body force [4]. Therefore, under our experimental conditions for this work, the stable laminar flame can be approximated as resulting from a competition between the hydrodynamic and thermodiffusive instabilities.

The hydrodynamic instability is a fluid mechanical effect that was originally discovered independently by Darrieus in 1938 [5] and Landau in 1944 [6]. It is caused by the thermal expansion of gases at the flame front, which leads to a temperature gradient that deviates from the flow line normal, causing a wrinkling effect at the flame front [7]. The thermodiffusive instability is caused by a preferential diffusion of mass versus heat in the immediate vicinity of the flame front depending on the Le of the deficient light reactant $[8,9]$ and is typically associated with flames near the flammability limits.

Spontaneous instability of a premixed flame front arises when combustion conditions either cause the competition between the above mentioned instabilities to be sufficiently diminished, or act in concert to destabilize the flame. For example, beginning with a stable laminar flame with a near-stoichiometric mixture, increasing the overall flow rate sufficiently will cause the flame front to take on a steady wrinkled geometry, indicating that the hydrodynamic instability is increasingly dominating over the competing thermodiffusive instability. Conversely, for a sufficiently small fixed flow rate to produce laminar flow, spontaneous instability can arise from the dominance of the thermodiffusive instability with the flame front evolving to a similarly wrinkled but unsteady shape [3]. Theoretical analyses of the thermodiffusive instability were first developed by Sivashinsky [10] for adiabatic flames, and then by Joulin and Clavin [11] for nonadiabatic flames. Following the qualitative descriptions of the thermodiffusive instability of Zeldovich [8] and Markstein [9] and the initial attempt at quantification of observed effects by Barenblatt et al. [12], they showed that a laminar flame would spontaneously exhibit thermodiffusive instability and take on a cellular structure when the Lewis number (Le) of the combusting mixture became smaller than unity $[10,11]$. Such a condition will occur if the molecular diffusivity of the species limiting the reaction exceeds the thermal diffusivity of the combusting mixture; i.e., the Lewis number of the deficient light reactant will determine the effective global Lewis number of the flame. Subsequent modeling work by Kadowaki [13] has shown that indeed as the Lewis number of a flame decreases, the thermod- iffusive instability of the flame increases, causing the overall flame stability to decrease.

Some of the more important combustion species and their associated Lewis numbers [14,15] have been published for conditions relevant to this work (stoichiometric mixtures, at one atmosphere). Collectively, such listings suggest that a limited number of light reactants would be capable of causing such a diminution of the effective Lewis number of a flame, specifically, atomic hydrogen and oxygen and the hydroxyl radical, which have species Lewis numbers of $0.18,0.70$, and 0.73 , respectively. For those species, the calculated Lewis numbers are essentially independent of temperature over the range of interest here (800-2200 K) [14]. Thus, control of the concentration and distribution of those radical species within a combusting mixture could produce a change of the thermodiffusive instability.

The results of the work reported here show that electric-field-induced instability of propane-air flames can be accomplished with the appropriate electrode geometry and modest applied potentials over a range of equivalence ratios, $\varphi$, spanning even near-stoichiometry. These effects are best described from a combustion dynamics viewpoint as a continuously variable electric-field-induced diminution [16] of the flame Lewis number from typical values to thermodiffusive-instability-dominated values [17] below unity at the higher applied potentials. Electricfield-driven flame-ion chemistry processes that could produce the observed effects are discussed in this paper.

\section{Governing theory}

The first detailed theories of the effect of electric fields on flames were introduced in the 1960 s by Lawton and Weinberg [18]. They used the ionic wind theory from discharges to explain the effects of an applied field on a flame that they and others observed. They described the ionic wind effect as the drag force that was experienced by the flame ions. Their theory predicts a maximum current density of $250 \mu \mathrm{A} / \mathrm{cm}^{2}$ using an $\sim 30-\mathrm{kV} / \mathrm{cm}$ applied electric field [18]. The maximum electric-field-induced pressure change predicted by this theory is only 0.0004 atm [18,19], which suggests that the ionic wind is not responsible for the large changes in flame structure that we see in our work. We have shown [16] previously that current densities comparable to the maxima stated for the ionic wind can be achieved with much smaller applied electric fields. Further, the associated observed effects on the flame [16] are much more pronounced than those observed in the ionic wind experiments. 
The term electric pressure [16] was used to explain the apparent difference between our results and those predicted by the ionic wind. Recent measurements suggest that the electric pressure acts through the manipulation of the instabilities in the flame by the production of light reactants at the burner head. Sivashinsky's review [10], and the references therein, describe the development of the understanding of flame pattern formation due to coupled hydrodynamic and thermodiffusive instabilities. Hydrodynamic instabilities tend to dominate at high flow velocities (or high Reynolds numbers), and it has been shown experimentally [7] that as the flow speed increases, so does the hydrodynamic instability of a premixed combusting flow.

Normally, the thermodiffusive instability is dominant only under conditions where $0.8>\varphi>1.3$, which naturally result in lower combustion temperatures (e.g., fuel-rich hydrocarbon flames or fuellean hydrogen flames). As discussed in papers by Sivashinsky [10], Williams [3], and Kadowaki [13], one method for increasing the strength of the thermodiffusive instability is to lower the flame global Le by providing a sufficient concentration of the deficient light reactant. In our work, this can be accomplished by the production of light radicals near the grounded burner head via dissociative recombination of important flame chemi-ions. Mass spectroscopic measurements by Goodings et al. [20] have shown that the majority ions present in a premixed hydrocarbon-air flame are $\mathrm{H}_{3} \mathrm{O}^{+}$and $\mathrm{HCO}^{+}$. The hydronium ion can dissociatively recombine through the four different channels shown below [21], with the probability that it will take each channel represented by $N$. $\mathrm{HCO}^{+}$, however, dissociatively recombines to form $\mathrm{H}+\mathrm{CO}$ :

$$
\mathrm{H}_{3} \mathrm{O}^{+}+e^{-} \rightarrow \begin{aligned}
& \mathrm{H}_{2} \mathrm{O}+\mathrm{H} \\
& \mathrm{OH}+\mathrm{H}_{2} \\
& \mathrm{OH}+2 \mathrm{H} \\
& \mathrm{O}+\mathrm{H}+\mathrm{H}_{2}
\end{aligned} \quad\left(\begin{array}{l}
N=0.05 \\
N=0.36 \\
N=0.29 \\
N=0.30
\end{array}\right) .
$$

If the chemi-ionization-derived positive ions are relocated to the immediate vicinity of the grounded burner head (preheat zone), the dissociative recombination of these two majority positive ions will result in a production of radicals into the preheat zone. Quantitative estimates of the levels of radicals required to effectively lower the Le of the flame so that the thermodiffusive instability dominates can be calculated by the current continuity equation,

$n_{\mathrm{H}_{3} \mathrm{O}^{+}} v_{\mathrm{d}, \mathrm{H}_{3} \mathrm{O}^{+}}+n_{\mathrm{HCO}^{+}} v_{\mathrm{d}, \mathrm{HCO}^{+}}=\frac{j}{e}$,

where $v_{\mathrm{d}}$ represents the drift velocity of the ion, $n$ is the number density, $j$ is the current density, and $e$ is the elementary charge. Treating the boundary between the base of the flame and the burner head as

\section{Flame Diagnostic Setup}

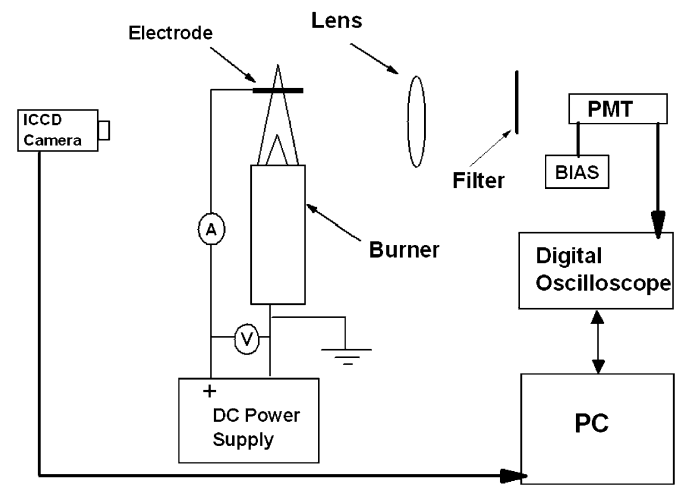

Fig. 1. Experimental configurations for high-speed twodimensional imaging, $I-V$, and flame oscillation measurements.

a cathode sheath allows us to substitute the Bohm velocity in place of the drift velocity. The Bohm velocity can be expressed by the equation [22]

$v_{\mathrm{B}}=\left(\frac{k T_{\mathrm{e}}}{m_{\mathrm{ion}}}\right)^{1 / 2}$,

where $k$ is Boltzmann's constant, $T_{\mathrm{e}}$ is the electron temperature, and $m_{\text {ion }}$ is the ionic mass. Using Eqs. (1) and (2) and the measured applied-voltageinduced current, it is possible to calculate the number densities of the light radicals that are required to produce the observed enhancements of the thermodiffusive instability.

\section{Experimental setup}

The principal setup, shown in Fig. 1, has been discussed in detail in a previous paper [16]. The DC current/voltage $(I-V)$ characteristics were recorded with the burner grounded and a bias of up to $+5 \mathrm{kV}$ being supplied to the upper electrode. Such measurements were used originally to investigate the degree of coupling of the flame to the electric field in an effort to increase the coupling efficiency. The upper electrode discussed here is a piece of perforated stainless steel that is suspended at a distance of $40 \mathrm{~mm}$ above the burner. This electrode allows a simple parallel-platelike electrode geometry at the expense of perturbing the gas flow downstream from the flame front. The DC field was applied to the flame through a $500-\mathrm{k} \Omega$ current-limiting ballast resistor that was connected between the anode and the bias supply, while the current measurements were made through a $100-\mathrm{k} \Omega$ current-sensing resistor placed between the floating burner and ground.

Images used to document the response of the flame to the applied field were obtained using a Princeton 
Instruments ICCD high-speed camera. With the aid of interference filters (10-nm bandpass), spectrally resolved images of chemiexcited flame radicals $\mathrm{CH}^{*}$, $\mathrm{OH}^{*}$, and $\mathrm{C}_{2}^{*}$ were also recorded. The small jets seen at the bottom of the flame are a result of a slight nonuniformity in the flow speed. Local variations of these chemiexcited radicals within the flame were also optically monitored using bandpass filters and an optical fiber lens (not shown) coupling selected portions of the flame image to the photomultiplier tube (PMT).

The fuel and air flow rates were set and monitored by ball-float-type flow meters capable of flow rates up to 2.7 standard liters per min (slm) for propane, and up to $66 \mathrm{slm}$ for air. Typical flow rates used for results reported here were between 5 and $25 \mathrm{slm}$ for air, with the corresponding flow rates for propane varied to provide the desired equivalence ratio. The equivalence ratio was calculated with the use of a LabVIEW program and calibration data for the fuel and air flowmeters. For most data reported here, the flow velocity was approximately $1.7 \mathrm{~m} / \mathrm{s}$, and the range of equivalence ratios used during this study was between 0.8 and 1.3. The propane used was a standard commercial grade, and the air was supplied by a building air compressor and drying unit.

\section{Results and discussion}

\subsection{Electrical measurements}

The most straightforward way to validate an effective coupling of the electric field to the flame is to obtain $I-V$ measurements of the flame. The $I-V$ characteristics of a flame with a premixed air and fuel flow rate of $21 \mathrm{slm}$ (flow velocity of $1.7 \mathrm{~m} / \mathrm{s}$ ) and equivalence ratio of 1.2 are shown in Fig. 2a. The points marked A, B, and C refer to bias potentials near where major modifications of the reaction zone geometry occurred. Point A locates the potential needed to cause the inner cone of the flame to be reduced in height and the flame to be made even more stable than the low-velocity, near-laminar flow inlet stream allows. For the conditions used to produce the $I-V$ curve of Fig. 2a, the cold-flow Reynolds number was near 2000. Point B indicates the potential needed to cause the inner cone to distort noticeably from cone shape and begin large-amplitude (audible) oscillations. Point $\mathrm{C}$ denotes the potential that must be applied to depress the entire reaction zone close to the burner head and induce a more intense, unstable motion of the reaction sheet. Another significant feature of the $I-V$ curve is that there is no indication of reaching a saturation current up to the maximum
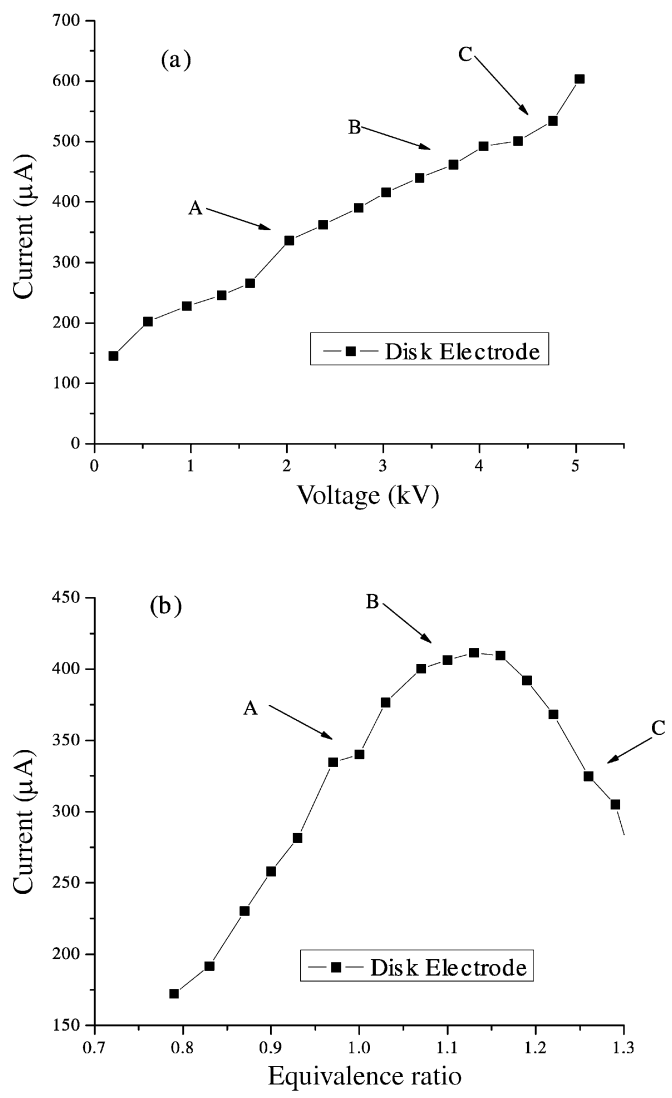

Fig. 2. (a) Typical $I-V$ characteristics measured for field-modified flames. Note that the total electrical power input is quite small ( $\sim 3 \mathrm{~W}$ at the highest bias). (b) Variation of flame current with equivalence ratio for a fixed air flow rate and a fixed positive external bias.

applied potential of $+5 \mathrm{kV}$. Also note that the maximum electrical power input is on the order of a few watts.

The effect of varying the fuel flow rate at a fixed air flow rate of $20 \mathrm{slm}$ and a fixed positive bias of $5 \mathrm{kV}$ is shown in Fig. 2b. These data essentially map the combined variation in flame conductivity and coupling to the external circuit as a function of equivalence ratio. The peak power input occurs at an equivalence ratio slightly above 1.1 . If the bias potential is reversed, the current drawn at a $+3 \mathrm{kV}$ bias is less than $10 \mu \mathrm{A}$, indicating a diode-like response of the flame to an external bias [16]. Points marked A, B, and C here mark the equivalence ratios that correspond to the collapse of the flame front near the burner head, similar to that shown in the flame images of Figs. 3-6, undergoing significant collective oscillation as shown by the fast Fourier transforms (FFT) in Fig. 7, and finally recovering from a collapsed flame front near the burner head, respectively. 

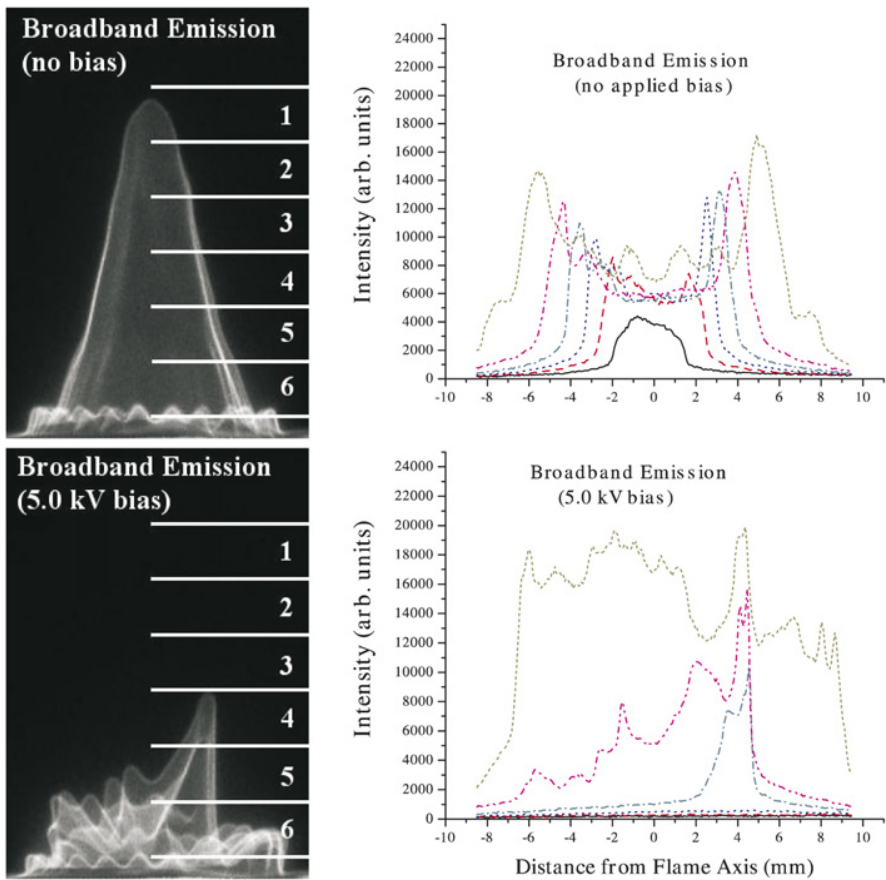

Fig. 3. Direct high-speed two-dimensional images of the flame response to a $+5 \mathrm{kV}$ bias. The intensity plot to the right shows the change in flame structure with the applied field.
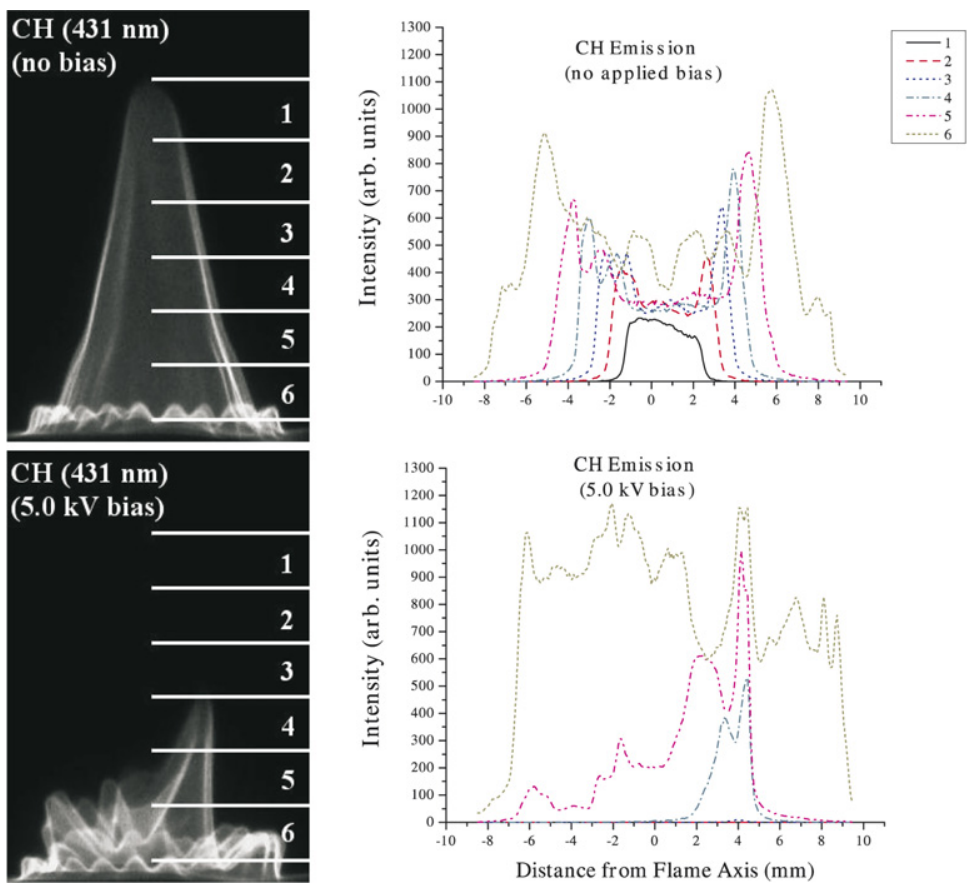

Fig. 4. High-speed two-dimensional images of flame response to a $+5 \mathrm{kV}$ bias taken with a bandpass filter to measure the $\mathrm{CH}^{*}$ emission. The intensity plot to the right shows the change in combustion intensity with the applied field. 

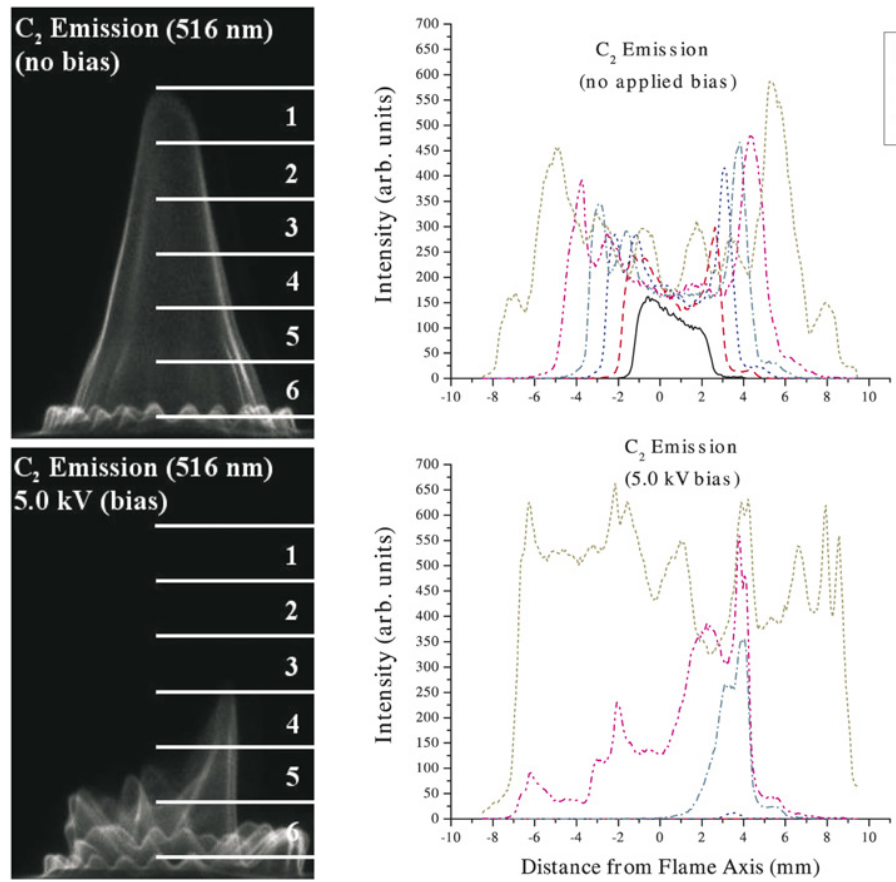

Fig. 5. High-speed two-dimensional images of flame response to a $+5 \mathrm{kV}$ bias taken with a bandpass filter to measure the $\mathrm{C}_{2}^{*}$ emission.
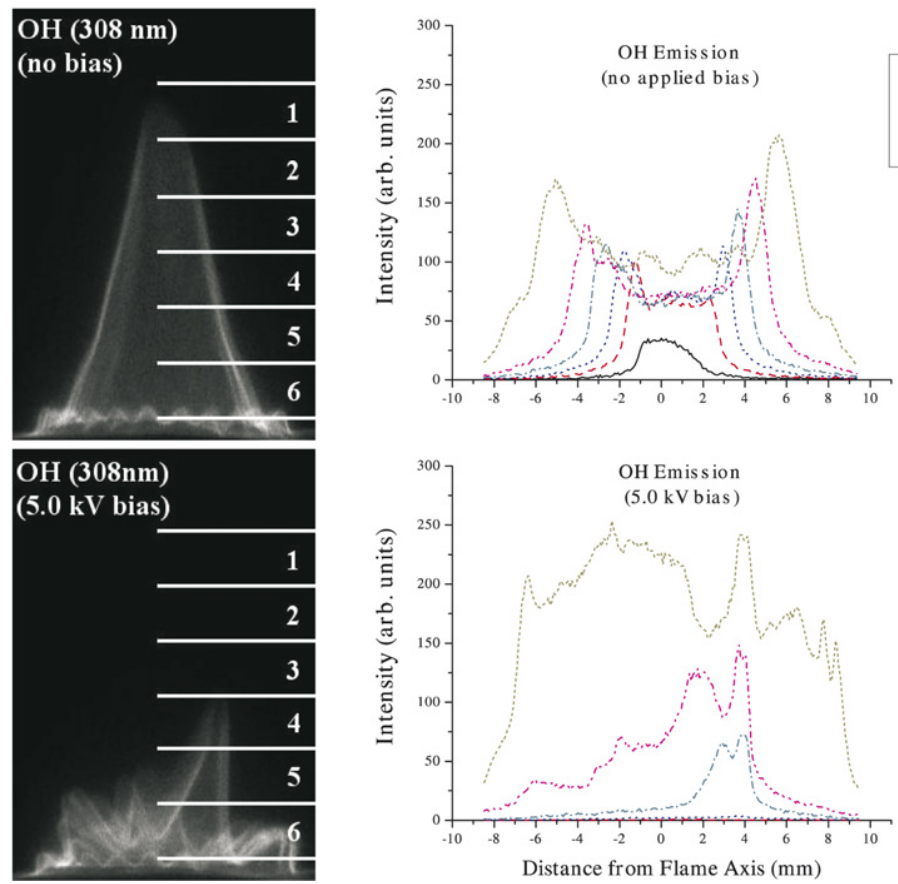

Fig. 6. High-speed two-dimensional images of flame response to a $+5 \mathrm{kV}$ bias taken with a bandpass filter to measure the $\mathrm{OH}^{*}$ emission. The intensity plot to the right shows the change of heat release and flame front location with the applied field. 

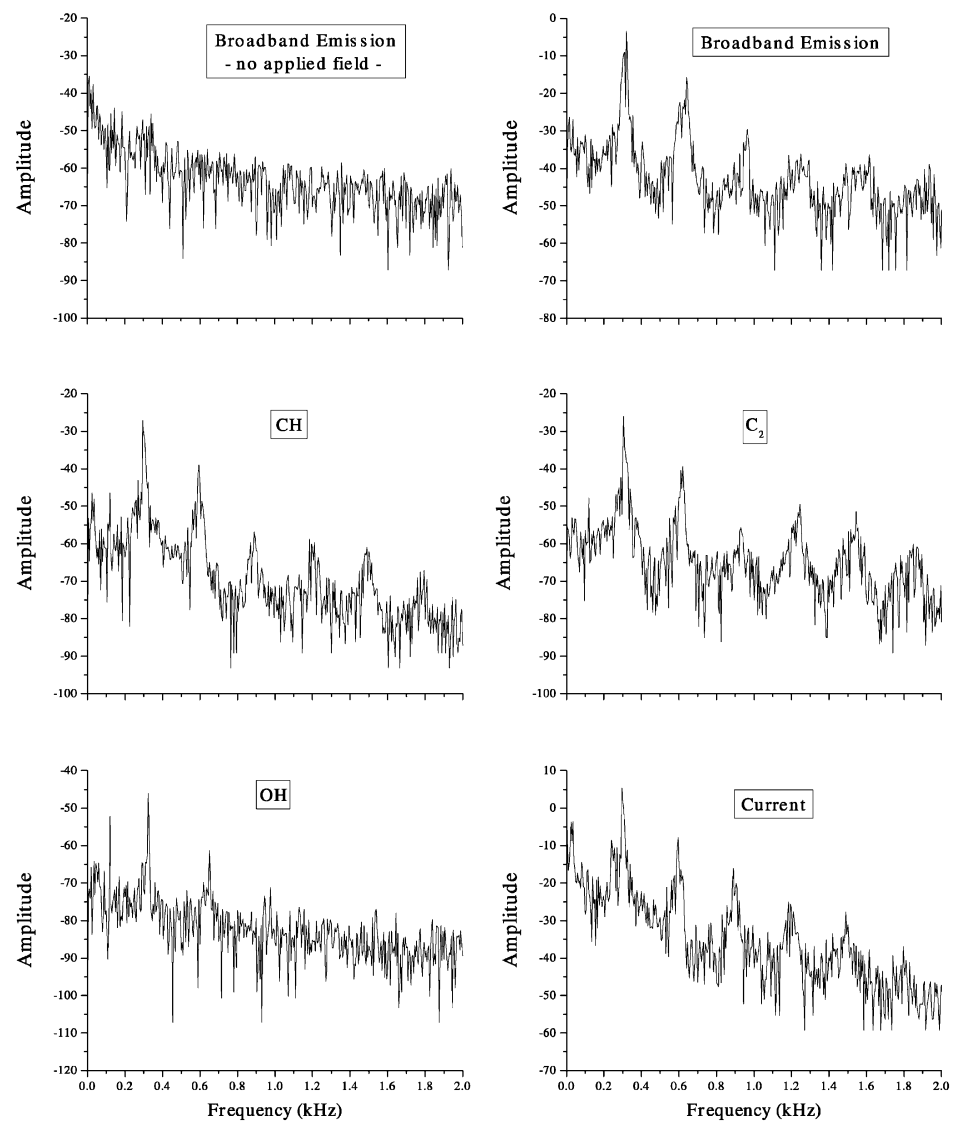

Fig. 7. Current and flame front optical signal oscillations using the same flame emissions as shown in Figs. 3-6 quantified by computing the power spectrum of the oscillatory signals. The top left graph has no applied voltage, whereas all other graphs have a positive applied voltage of $+5.2 \mathrm{kV}$.

\subsection{Dissociative recombination derived radical number density estimates}

To calculate the level of light radicals produced in the preheat zone by the applied electric field, in addition to measuring the current through the flame, the electron temperature at the burner head must be determined for substitution into Eq. (2). For the measurement condition of low reduced electric field $(E / n)$, the electron temperature can be approximated as the gas temperature. For experimental conditions discussed here, the reduced electric field is below $3 \mathrm{Td}$ ( $\left.1 \mathrm{Td}=10^{-17} \mathrm{~V} \mathrm{~cm}^{2}\right)$, validating the low reduced electric field approximation. The ion number density in Eq. (1) can be estimated from current values on the $I-V$ curve of Fig. $2 \mathrm{a}$, and the associated cathode sheath area at the burner head. In order to provide a temperature estimate we used an infrared pyrometer to measure a temperature at the burner head to be $800 \mathrm{~K}$, and since we know the gas temperature should be near equilibrium with the temperature of the burner head, we can use this as an estimate for the gas tem- perature. Since the gas temperature will be slightly lower than the electron temperature, we estimate an electron temperature of $1000 \mathrm{~K}$.

Using the temperature estimated above, and the ion number density corresponding to the three points on the $I-V$ curve in Fig. 2a, it is possible to obtain an estimate of the level of dissociative recombinationderived radicals needed to be produced into the preheat zone to cause the observed flame modifications. The results of our calculations are presented in Table 1 . Those results assume a $90 \%$ majority ion concentration of $\mathrm{H}_{3} \mathrm{O}^{+}$, as suggested by experimental data $[19,20]$.

Note that number densities $\sim 10^{10} \mathrm{~cm}^{-3}$ of $\mathrm{H}$, $\mathrm{OH}$, and $\mathrm{O}$ radicals are being produced in an area of the preheat zone with a temperature of approximately $800 \mathrm{~K}$ through the dissociative recombination of flame positive chemi-ionization-produced ions at the burner head, which would far exceed the direct combustion-kinetics-driven production of $\mathrm{OH}$ and $\mathrm{H}$ $[23,24]$ in this range of gas temperature. We propose that the radicals act to increase the concentrations of 
Table 1

Number densities of chemi-ionization-derived positive flame ions and electric-field-induced dissociative recombination produced radicals at the base of a premixed propane/air flame for the different current values on the $I-V$ curve of Fig. 2a, indicated by points A, B, and C

\begin{tabular}{llll}
\hline & $\mathrm{A}(350 \mu \mathrm{A})$ & $\mathrm{B}(450 \mu \mathrm{A})$ & $\mathrm{C}(525 \mu \mathrm{A})$ \\
\hline Ions $\left(\mathrm{cm}^{-3}\right)$ & $1.26 \times 10^{11}$ & $1.62 \times 10^{11}$ & $1.88 \times 10^{11}$ \\
$\mathrm{H}\left(\mathrm{cm}^{-3}\right)$ & $1.18 \times 10^{11}$ & $1.51 \times 10^{11}$ & $1.77 \times 10^{11}$ \\
$\mathrm{OH}\left(\mathrm{cm}^{-3}\right)$ & $7.35 \times 10^{10}$ & $9.45 \times 10^{10}$ & $1.10 \times 10^{11}$ \\
$\mathrm{O}\left(\mathrm{cm}^{-3}\right)$ & $3.39 \times 10^{10}$ & $4.36 \times 10^{10}$ & $5.09 \times 10^{10}$ \\
$\mathrm{H}_{2}\left(\mathrm{~cm}^{-3}\right)$ & $7.46 \times 10^{10}$ & $9.59 \times 10^{10}$ & $1.12 \times 10^{11}$ \\
$\mathrm{CO}\left(\mathrm{cm}^{-3}\right)$ & $1.26 \times 10^{10}$ & $1.62 \times 10^{10}$ & $1.88 \times 10^{10}$ \\
\hline
\end{tabular}

deficient light reactants which have high mass diffusivities in the preheat zone of the flame, leading to an overall reduction of the local flame Le to numbers less than unity, which allows the thermodiffusive instability to dominate in the flame. These light radical productions are also most likely causing the observed flame speed increase due to increased reactant diffusion and local reaction rates [25-27], as discussed below.

\subsection{High-speed two-dimensional imaging}

Typical broadband and optical spectral emissions of flame response to an applied electric field are shown on the left-hand sides of Figs. 3-6. Figs. 3-6 were recorded from a premixed propane/air flame with a flow rate of $21 \mathrm{slm}$ and an equivalence ratio of 1.2 , corresponding to a flow velocity of $1.68 \mathrm{~m} / \mathrm{s}$. Fig. 3 shows a broadband image of the flame taken with an exposure time of $500 \mu$ s, which is a sufficiently short time to freeze all motion of the unstable flame front in the case of the field-perturbed flame. As noted earlier, the spectral emissions for $\mathrm{CH}^{*}, \mathrm{C}_{2}^{*}$, and $\mathrm{OH}^{*}$ were taken by placing the appropriate 10-nm bandpass filter in front of the camera optics. Figs. 4, 5, and 6 correspond to $\mathrm{CH}^{*}, \mathrm{C}_{2}^{*}$, and $\mathrm{OH}^{*}$ radical emission images, taken with exposure times of 10, 10, and $20 \mathrm{~ms}$, respectively. The use of chemiluminescence measurements to obtain information about flame chemistry, heat release, and flame structure has been widely reported [28-33]. Specifically, recent work [28-31] has shown that $\mathrm{OH}^{*}$ $\left(\mathrm{CH}+\mathrm{O}_{2} \rightarrow \mathrm{CO}+\mathrm{OH}^{*}\right)$ chemiluminescence signals can be used as a combustion diagnostic tool to gauge the relative change in combustion heat release and as a marker for the flame front [32]. The blurring of the flame fronts in Figs. 4-6 when there is an applied field is due to the necessarily longer exposure times of the camera and the short time scale of the intense induced instability. Adjacent to each ICCD image is a set of intensity profiles that correspond to the emission intensity as a function of distance from the flame axis for each of the six horizontal zones marked on the corresponding flame image.

As can be seen from these figures, once the voltage is applied, causing a production of light radicals in the preheat zone, the flame goes from a stable, quasilaminar situation to a thermodiffusive-instabilityinduced unstable flame that is typical of flames with Le less than unity $[10,11,17,25,26]$. Those data suggest that the electric-field-induced radical production causes the combustion intensity of the burner to be enhanced by increasing the flame speed through the introduction of deficient light reactants into the preheat zone, and thereby reducing the flame Lewis number to values below unity. This can also be viewed as confining the same amount of heat release (i.e., the total intensity does not change, it is just relocated) to a smaller volume through the increase in the wrinkled flame surface area, which is clearly visible from the chemiluminescence images shown in Figs. 4-6. The different zones in the flame are all of the same size, and correspond to the intensity profiles to the right of the image. As can be seen in Fig. 3, once the electric field has been applied, the broadband flame emission intensity in zones 1-3 approaches a zero value, and the average intensity in the remaining zones increases significantly over the zero-field case. This same trend continues for the $\mathrm{CH}^{*}, \mathrm{OH}^{*}$, and $\mathrm{C}_{2}^{*}$ chemiluminescence emissions, as shown in Figs. 4-6, indicating a significant level of thermodiffusive instability.

\subsection{Flame oscillation characterizations}

The final data reported here are derived from measurements of the flame conduction current and flamefront optical signal oscillations, the latter having been measured with a combination of optical bandpass filter and a photomultiplier tube as previously mentioned. Fig. 7 shows a series of FFTs of broadband and spectrally filtered flame front emissions, as well as the FFT of the oscillating current drawn from the external bias supply. Again, the experimental conditions are the same as those used for the imaging data shown in Figs. 3-6, except that the bias used is $+5.2 \mathrm{kV}$ (corresponding to point $\mathrm{C}$ in the $I-V$ curve of Fig. 2a).

The top left FFT of Fig. 7 shows the very lowamplitude, featureless power spectrum of the flame's broadband emissions under zero bias, indicating a stable and laminar flow. With a $+5.2 \mathrm{kV}$ bias the flame front is driven into a large-amplitude resonate-like audible oscillation with a fundamental frequency near $300 \mathrm{~Hz}$ and harmonics ranging up to $1.8 \mathrm{kHz}$. Essentially the same responses are seen again from broadband emissions and those corresponding to chemiexcited $\mathrm{CH}^{*}, \mathrm{C}_{2}^{*}$, and $\mathrm{OH}^{*}$. Further, the current passing through the flame exhibits a power spectrum 
that is essentially identical to that of the flame front emissions. These high-frequency fluctuations of the chemiluminescent intensities are also indicative of the transition of the premixed propane/air laminar flame to a highly unstable flame due to the lowering of the flame Lewis number through dissociative recombination of the flame-produced positive ions.

\section{Conclusions}

Under the flow conditions that are presented here, we have shown that it is possible to modify a laminar flame, which exhibits a highly symmetric right circular cone geometry, to an unstable flame due to an induced thermodiffusive instability by the production of radicals through the dissociative recombination of flame ions. We have proposed a plausible explanation whereby such transitions are caused by the production of light radicals into the preheat zone, which in turn reduces the flame Lewis number for premixed $\mathrm{C}_{3} \mathrm{H}_{8} /$ air flames.

The electric field acts directly on the highly localized, chemi-ionization-derived $\mathrm{H}_{3} \mathrm{O}^{+}, \mathrm{HCO}^{+}$, and other positive ions in the flame reaction zone, forcing them to move toward the grounded burner head, where they can dissociatively recombine, causing the production of radicals in the preheat zone. The radicals that are produced in the low temperature preheat zone have high mass diffusivities, which result in the decrease of the local Lewis number of the flame. The observed result is a thermodiffusive-instabilitydominated flame structure, typical of flames with global Lewis numbers less than unity. The increased differential diffusional velocity of the reaction zone positive ions strongly affects the bulk flame speed, and the instability results in the flame front collapsing toward the burner head and taking on an oscillating, wrinkled laminar geometry, or exhibiting instabilities. An approximate estimate of the positive ion flux, assuming the ion flux consists of $x \mathrm{H}_{3} \mathrm{O}^{+}$and $(1-x) \mathrm{HCO}^{+}$only, and the corresponding production of $\mathrm{H}, \mathrm{OH}$, and $\mathrm{O}$ radical flux through dissociative recombination has been estimated. As was reported earlier [14,15], the Le of those radical species is lower than the Lewis numbers of hydrocarbon flames.

It has also been shown that by producing radicals through dissociative recombination of flame positive ions in the preheat zone, it is possible to increase the combustion intensity of the burner through a flame speed modification that accompanies the lowering of the Lewis number. We expect that it should be possible to observe similar effects for other premixed heavy hydrocarbon flames.

\section{Acknowledgments}

This work was supported in part by the Air Force Office of Scientific Research (AFOSR), Dr. Julian Tishkoff, technical monitor. D.L. Wisman acknowledges the Student Temporary Employment Program (STEP) with the Air Force Research Laboratory, and S.D. Marcum acknowledges the Air Force Research Laboratory summer faculty program for partial funding of this work. All work was performed at WrightPatterson AFB, Ohio.

\section{References}

[1] G.I. Sivashinsky, Annu. Rev. Fluid Mech. 15 (1983) 179-199.

[2] P. Clavin, Prog. Energy Combust. Sci. 11 (1985) 1-59.

[3] F.A. Williams, Combustion Theory, second ed., Addison-Wesley, Reading, MA, 1985, pp. 341-365.

[4] S. Kadowaki, Phys. Rev. E 63 (2001) 026303.

[5] G. Darrieus, Propagation d'un front de flame: assai de theorie des vitesses anomales de deflagration par developpement spontane de la turbulence, communication presented at La Technique Moderne, 1938.

[6] L.D. Landau, Acta Physicochim. 19 (1944) 77-85.

[7] C. Clanet, G. Searby, Phys. Rev. Lett. 80 (1998) 38673870.

[8] Y.B. Zeldovich, Theory of Combustion and Detonation of Gases, USSR Academy of Sciences, Moscow, 1944 (in Russian).

[9] G.H. Markstein, J. Chem. Phys. 17 (1949) 428-429.

[10] G.I. Sivashinsky, Combust. Sci. Technol. 15 (1977) 137-145.

[11] G. Joulin, P. Clavin, Combust. Flame 35 (1979) 139153.

[12] G.I. Barenblatt, Y.B. Zeldovich, A.G. Istratov, J. Appl. Mech. Tech. Phys. 4 (1962) 21-26 (in Russian).

[13] S. Kadowaki, Combust. Flame 143 (2005) 174-182.

[14] M. Smooke, Reduced Kinetic Mechanisms and Asymptotic Approximations for Methane-Air Flames, Lecture Notes in Physics, Springer-Verlag, Berlin, 1991, pp. 1-28.

[15] J.H. Chen, T. Echekki, W. Kollmann, Combust. Flame 116 (1999) 15-47.

[16] S.D. Marcum, B.N. Ganguly, Combust. Flame 143 (2005) 27-36.

[17] J. Yaun, Y. Ju, C.K. Law, Phys. Fluids 17 (2005) 1-10.

[18] J. Lawton, F. Weinberg, Proc. R. Soc. London Ser. A 277 (1964) 468-497.

[19] T. Pedersen, R. Brown, Combust. Flame 94 (1993) 433-448.

[20] J.M. Goodings, D.K. Bhome, C. Ng, Combust. Flame 36 (1979) 27-43.

[21] L. Veiby-Christensen, L.H. Andersen, O. Heber, D. Kella, H.B. Pedersen, H.T. Schmidt, D. Zajfman, Astrophys. J. 483 (1997) 531-540.

[22] K. Riemann, J. Phys. D Appl. Phys. 24 (1991) 493-518.

[23] V.R. Katta, T.R. Meyer, M.S. Brown, J.R. Gord, W.M. Roquemore, Combust. Flame 137 (2004) 198-221. 
[24] T.R. Meyer, S. Roy, T.N. Anderson, J.D. Miller, V.R. Katta, R.P. Lucht, J.R. Gord, Appl. Opt. 44 (2005) 6729-6740.

[25] C.J. Rutland, A. Trove, Combust. Flame 94 (1993) 4157.

[26] N. Chakraborty, R.S. Cant, Int. J. Heat Mass Transfer 49 (2006) 2158-2172.

[27] S.M. Starikovskaia, J. Phys. D Appl. Phys. 39 (2006) R265-R299.

[28] J. Kojima, Y. Ikeda, T. Nakajima, Combust. Flame 140 (2005) 34-45.
[29] Y. Hardalupas, M. Orain, Combust. Flame 139 (2004) 188-207.

[30] Y. Hardalupas, C.S. Panoutsos, A.M.K.P. Taylor, in: 44th Aerospace Sciences Meeting, Reno, NV, 2006, AIAA, Paper AIAA-2006-1450.

[31] C.J. Lawn, Combust. Flame 123 (2000) 227-240.

[32] J. Kojima, Y. Ikeda, T. Nakajima, in: 35th Joint Propulsion Conference, Los Angeles, CA, 1999, AIAA, Paper AIAA-99-2784.

[33] A.B. Fialkov, Prog. Energy Combust. Sci. 23 (1997) 399-528. 